\title{
Change in physicochemical characteristics and molecular weight distribution of glutenin macropolymer induced by postharvest wheat maturation
}

\author{
Y. Yue, X. Liu, J. Wang", F. Jia, Q. Wang and X. Zhang \\ College of Biological Engineering, Henan University of Technology, Zhengzhou 450001, China P.R.; jinshuiw@163.com
}

Received: 11 July 2019 / Accepted: 18 November 2019

(c) 2019 Wageningen Academic Publishers

OPEN ACCESS C9) RESEARCH ARTICLE

\begin{abstract}
The present study was aimed to investigate change in physicochemical characteristics and glutenin macropolymer (GMP) molecular weight distribution during postharvest wheat maturation. The freshly harvested wheat was stored under four different conditions (WT1, WT2, WT3 and WT4) for specified times. During maturation, the strengthening of wheat gluten structure was observed by increase in gluten index, swelling index of glutenin and sodium dodecyl sulphate (SDS) sedimentation value. The postharvest maturation resulted in contents increase of glutenin, glutenin/gliadin ratio, and GMP, and the decline of gliadin content. The contents of free sulfhydryl in GMP reduced, and S-S content rose during the whole maturation. Visible aggregates of GMP were observed in SDS-PAGE patterns for WT3 and WT4 samples after 4 weeks of storage. Moreover, in these two samples, polymerisation of gluten proteins into GMP was observed in size-exclusion high performance liquid chromatography patterns during storage. Some low molecular weight glutenin subunits (LMW-GS) incorporated into the aggregate, or combination of high molecular weight glutenin subunits and LMW-GS formed large polymeric glutenins by S-S linkage, and then assembled into GMP in postharvest wheat maturation. GMP polymerisation probably results in the improvement of wheat quality.
\end{abstract}

Keywords: wheat, postharvest maturation, physicochemical properties, glutenin macropolymer, molecular weight distribution

\section{Introduction}

Wheat is one of the most important cereals in the world. As a staple food material, wheat foods provide most of energy, protein for people all over the world (Aghababaei et al., 2017). China is the largest wheat producer and consumer in the world. Wheat is particularly widely planted in northern China. Newly harvested wheat has poor milling, processing and nutritional quality. The wheat has a postharvest maturation phenomenon, and postharvest maturation begins after harvest and continues in storage depending on time and conditions of storage. After a series of biochemical and colloidal changes, wheat reaches to the technological and eating maturity during the storage (Tomić et al., 2013). Therefore, the wheat postharvest maturation is an important part of baking and technological quality improvement (Janić et al., 2014).
Protein and starch are the major constituents of wheat wherein gluten proteins play an important role in the production of different wheat and wheat-based products. Wheat flour is unique for forming viscoelastic dough when mixed with water due to the formation of gluten (Lindsay and Skerritt, 1999). Gluten polymers are among the largest and most complex protein networks in nature with molecular weights of more than 10 million (Wieser, 2007). Gluten proteins are storage proteins and divided into two major fractions according to differences in solubility: the monomeric gliadins and the polymeric glutenins. Gliadins and glutenins are responsible for the viscoelastic properties of wheat flour dough. Gliadins contribute to the viscous properties of wheat four dough (Pomeranz, 1988), whereas glutenin fraction has long been considered to have a prominent role in strength and elasticity to the dough (MacRitchie, 1980; Weegels et al., 1996). Viscoelasticities of glutens are governed by glutenin compositions, gliadin/ 
glutenin ratio, and high molecular weight glutenin subunits (HMW-GS) / low molecular weight glutenin subunits (LMW-GS) ratio. These properties also affect rheological properties and technological quality of wheat flour (Koga et al., 2017; Song and Zheng, 2007). Glutenin subunits form both intra- and inter-chain disulphide bonds, while gliadins are only capable of forming inter-chain disulphide bonds. Differences in the disulphide bonding properties of glutenin subunit impact on their association within the glutenin macropolymer (GMP), and role in establishing gluten structure and subsequent function (Lindsay and Skerritt, 1999). GMP is an important fraction of the glutenins isolated from wheat flour as a sodium dodecyl sulphate (SDS) insoluble gel-layer (Weegels et al., 1996). GMP consists of spherical glutenin particles (Don et al., 2003a,b). There is also great difference of size of GMP, and this variation correlates with a key technological quality parameter (Don, 2005). The importance of GMP in assessing wheat quality and predicting dough properties has been confirmed (Sapirstein and Suchy, 1999). Significant correlations between GMP in flour and quality parameters, such as loaf and physical dough properties, have been observed (Dachkevitch and Autran, 1998; Gupta et al., 1993; Wang et al., 2007).

Storage in favourable condition causes some biochemical and physicochemical changes of the wheat grains. The storage is also an aging process, in which the physicochemical properties, dough viscosity and end-use quality of wheat are improved considerably (Aghababaei et al., 2017). Moreover, the ageing process of these freshly harvested grains was initiated by the control of three factors including storage temperature, moisture content and duration of storage. In China, there are complex and changeable stored-grain ecosystems. To the best our knowledge, there is little information about the mechanism induced quality improvement during postharvest wheat maturation in different stored-grain ecosystem. This study thus aimed to investigate the combined effect of storage temperature, moisture content and storage time on physicochemical characteristics of postharvest wheat maturation, and analysed the composition change of GMP in postharvest wheat maturation.

\section{Materials and methods}

\section{Wheat sample and storage}

Wheat samples (Luomai18), a hard white winter wheat, were obtained from growing region in Yuzhou, Henan, China. The variety is one of the widely planted varieties in the local area and is suitable for making fermented food such as steamed bread and bread, wheat was harvested in 2017. All samples were free from insect infestation and winnowed and the broken grains were separated. The freshly harvested wheat samples were kept for 3 days under laboratory condition, and then were treated. About $10.0 \mathrm{~kg}$ wheat samples were placed in the air tight buckets of uniform size for each treatment. These buckets were stored in constant temperature and humidity incubator under four different conditions $\left(15^{\circ} \mathrm{C} / 50 \% \mathrm{RH}, \mathrm{WT} 1\right.$; $20^{\circ} \mathrm{C} / 65 \% \mathrm{RH}$, WT2; $28^{\circ} \mathrm{C} / 75 \% \mathrm{RH}$, WT3 and $35^{\circ} \mathrm{C} / 85 \% \mathrm{RH}$, WT4) for specified times. Samples were emptied into big boxes to bring back the grains to room temperature before milling. The samples were individually milled by high speed pulveriser, the extraction rate is about $70 \%$. The size of powder should be less than 60 mesh. The lab environment was $25{ }^{\circ} \mathrm{C}$ and $45 \% \mathrm{RH}$. The conditioned samples were then milled using a laboratory miller (RT-34, Hongquan Pharmaceutical Machinery Ltd., Hong Kong, China) after passing the required storage time.

\section{Determination of wet gluten and gluten index}

Wet gluten and gluten index of stored wheat samples were measured in a Glutomatic system (Perten, Stockholm, Sweden) following American Association of Cereal Chemists International approved method of 38.12-02 (AACCI, 2010). Washed gluten was kept in a shaking water bath at $37^{\circ} \mathrm{C}$ for different time intervals, and then determination of wet gluten and the gluten index were made according to the standard methods.

\section{Protein analysis}

Wheat flour protein content was determined by the Kjeldahl method. Protein content of gliadin, glutenin, GMP was measured using a UV absorption method (Hall, 1996). The UV method was successfully calibrated using a set of known gliadin, glutenin, GMP values determined by the Kjeldahl method.

\section{Isolation of gliadin, glutenin and glutenin macropolymer}

Briefly, $1 \mathrm{~g}$ of whole wheat flour were suspended in $10 \mathrm{ml}$ of $1 \mathrm{~mol} / \mathrm{l} \mathrm{NaCl}$ solution and magnetically stirred for $30 \mathrm{~min}$ (700 rpm) at RT. The suspension was then centrifuged for $10 \mathrm{~min}$ at $10,000 \times g$ at $25^{\circ} \mathrm{C}$. The supernatant was albumin and globulin. The pellet was suspended in $10 \mathrm{ml}$ of $70 \%$ ethanol and magnetically stirred for $30 \mathrm{~min}$ (700 rpm) at RT. The suspension was then centrifuged for $10 \mathrm{~min}$ at $10,000 \times g$ at $25^{\circ} \mathrm{C}$. The supernatant and the pellet were gliadin and glutenin, respectively.

The wheat flour defatted with petroleum ether was suspended in $1.5 \%$ SDS ( $1.4 \mathrm{~g}$ flour in $28 \mathrm{ml}$ ) and centrifuged at $10,000 \times g$ for $20 \mathrm{~min}$ at $4{ }^{\circ} \mathrm{C}$ (Graveland et al., 1982). The supernatant was discarded and the gel-layer collected as GMP. 


\section{Free sulfhydryl groups and disulphide bonds of glutenin macropolymer}

Disulphide (SS) and free sulfhydryl (SH) contents of GMP were determined according to the method of Anderson and $\mathrm{Ng}$ (2007) with some modifications. GMP was dissolved in $5.0 \mathrm{ml}$ buffer A (buffer A, pH 8.0 containing $8 \mathrm{~mol} / \mathrm{l}$ urea, $3 \mathrm{mmol} / \mathrm{l} \mathrm{EDTA,} 1 \% \mathrm{SDS}$ and $0.2 \mathrm{~mol} / \mathrm{l}$ Tris- $\mathrm{HCl}$ ), and the mixtures were shaken for $1 \mathrm{~h}$. After that, $1.0 \mathrm{ml}$ buffer $B$ (buffer B, pH 8.0, 10 mmol/l DTNB, 0.2 mol/l Tris-HCL) was added. Then, the mixtures were shaken for $1 \mathrm{~h}$, the suspension was centrifuged for $10 \mathrm{~min}$ at $10,000 \times g$ at $25^{\circ} \mathrm{C}$. Exactly, the absorbance of the supernatant was measured at $412 \mathrm{~nm}$.

Then, $500 \mathrm{mg}$ whole wheat flour were suspended in $10 \mathrm{ml}$ of a SDS solution $(1.5 \%, \mathrm{w} / \mathrm{v})$ and magnetically stirred for $1 \mathrm{~h}$ at RT. The pellet was suspended in $5 \mathrm{ml}$ of buffer $\mathrm{C}$ (buffer C, pH 9.5 containing $8 \mathrm{~mol} / \mathrm{l}$ urea, $3 \mathrm{mmol} / \mathrm{l}$ EDTA, 1.0\% (w/v) SDS, $0.1 \mathrm{~mol} / 1 \mathrm{Na}_{2} \mathrm{SO}_{3} 0.5 \mathrm{mmol} / \mathrm{NTSB}^{2-}$ and 0.2 $\mathrm{mol} / \mathrm{l}$ Tris-HCL) and shaken for $1 \mathrm{~h}$ at $25^{\circ} \mathrm{C}$, the suspension was centrifuged for $10 \mathrm{~min}$ at $10,000 \times g$ at $25^{\circ} \mathrm{C}$. the $0.1 \mathrm{ml}$ supernatant was drew, add $0.9 \mathrm{ml}$ buffer D (buffer D, pH 8.0 containing $8 \mathrm{~mol} / \mathrm{l}$ urea, $3 \mathrm{mmol} / \mathrm{l}$ EDTA, 1.0\% (w/v) SDS, $0.1 \mathrm{~mol} / 1 \mathrm{Na}_{2} \mathrm{SO}_{3}, 0.2 \mathrm{~mol} / \mathrm{l}$ Tris-HCL), the absorbance of the supernatant was measured at $412 \mathrm{~nm}$.

Absorbance values were converted to level of $\mathrm{SH}$ : $\mathrm{A}=\varepsilon \mathrm{bc}$.

(A is light absorption value (OD); $\varepsilon$ (molar absorption coefficients $)=13,600 \mathrm{l} /(\mathrm{mol} \cdot \mathrm{cm})$; $\mathrm{b}$ is the thickness of cuvette; $\mathrm{c}$ is the concentration of the test sample)

Values of the content of disulphide bonds: $\mathrm{SS}=(\mathrm{TS}-\mathrm{SH}) / 2$

(SS is the content of disulphide bonds; TS is the content of the total sulfhydryl groups; $\mathrm{SH}$ is the content of free sulfhydryl)

\section{Analysis of SDS-PAGE}

GMP was suspended in $1.0 \mathrm{ml}$ of sample buffer [containing $0.01 \mathrm{~mol} / \mathrm{l}$ Tris- $\mathrm{HCl}(\mathrm{pH}$ 6.8), 10\% (w/v) SDS, 10\% (v/v) glycerol and $0.1 \%(\mathrm{w} / \mathrm{v})$ bromophenol blue, $5 \%(\mathrm{v} / \mathrm{v})$ 2-mercaptoethanol (2-ME)] and left for $1 \mathrm{~h}$. Samples were heated for $5 \mathrm{~min}$ at $100{ }^{\circ} \mathrm{C}$ and centrifuged for $10 \mathrm{~min}$ at $8,000 \times g$. GMP proteins were subjected to SDS-PAGE. SDS-PAGE analysis of proteins was performed in a vertical electrophoresis cell using 10\% separating gel ( $\mathrm{pH} 8.8)$ and $5 \%$ stacking gel ( $\mathrm{pH} 6.8$ ). GMP proteins on the gel were stained with coomassie brilliant blue R-250 and destained in $7 \%(\mathrm{v} / \mathrm{v})$ acetic acid.

\section{Size-exclusion high performance liquid chromatography}

The extraction of samples was referred to literature and improved (Labuschagne et al., 2006). $170 \mathrm{mg}$ of wheat flour sample was suspended in $15 \mathrm{ml}$ of a $0.1 \mathrm{~mol} / \mathrm{l}$ sodium phosphate buffer ( $\mathrm{pH} 6.9$ ) containing $0.5 \%$ (w/v) SDS. The mixture was shook at room temperature for $120 \mathrm{~min}$. The suspensions were centrifuged for $15 \mathrm{~min}$ at $10,000 \times g$. A clear supernatant was obtained after filtration through a $0.45 \mu \mathrm{m}$ membrane. The protein extracts were loaded on Biosep-SEC-S4000 column with a separation range from 15 to $500 \mathrm{kDa}(300 \times 7.8 \mathrm{~mm}$, Phenomenex, Torrance, CA, USA), performed on a liquid Biosep-SEC system. The elution solvent was acetonitrile/water $(1: 1, \mathrm{v} / \mathrm{v})$ containing $0.1 \%(\mathrm{v} / \mathrm{v})$ trifluoroacetic acid $(\mathrm{v} / \mathrm{v})$ with a flow rate of 0.1 $\mathrm{ml} / \mathrm{min}$ at ambient temperature for $30 \mathrm{~min}$. Protein elution was monitored at $280 \mathrm{~nm}$.

\section{Statistical analysis}

All the data obtained in the study were expressed as the mean of three parallel experiments. Analysis of variance (ANOVA) was performed using the software SPSS16.0 (SPSS Inc., Chicago, IL, USA) with one-way analysis of variance (ANOVA) and Duncan's multiple-range test (Chaudhary et al., 2016). $P<0.05$ was used to define the significance of differences between the samples.

\section{Results and discussion}

\section{Effect of storage on wet gluten and gluten index of stored wheat}

Wheat quality is determined by several variables including: grain physical properties, protein content and composition, and starch content. Among the quality characteristics, storage protein content has been found to be the most important quality feature for wheat (Dowell et al., 2008). Moreover, variation in total protein content alone does not adequately explain the variation in food-making quality, as protein quality is an important factor as well (Bonfil and Posner, 2012; Peterson et al. 1986). Wheat gluten proteins including glutenin and gliadin are of immense importance in the food industry as their properties underpin the processing of wheat flour to produce the end foods. Wet gluten content and gluten index (GI) are usually used as the wheat quality traits.

Table 1 shows the effect of storage time on wet gluten content of wheat. No significant differences $(P<0.05)$ were found in the amounts of wet gluten as a consequence of storage time for the four samples. In particular, there were no obvious changes in the amounts of wet gluten with storage time for wheat samples (WT1 and WT2) stored in $15{ }^{\circ} \mathrm{C}, 50 \% \mathrm{RH}$ and $20{ }^{\circ} \mathrm{C}, 65 \% \mathrm{RH}$. For wheat samples (WT3 and WT4) stored in $28^{\circ} \mathrm{C}, 75 \% \mathrm{RH}$ and $35^{\circ} \mathrm{C}, 85 \%$ 
Table 1. Change in physicochemical properties of freshly-harvested wheat during the postharvest maturation. ${ }^{1}$

\begin{tabular}{|c|c|c|c|c|c|}
\hline Storage duration/W & & WT1 & WT2 & WT3 & WT4 \\
\hline \multirow[t]{8}{*}{ Wet gluten content (\%) } & 0 & $30.99 \pm 0.23 a$ & $30.99 \pm 0.23 a$ & $30.99 \pm 0.23 a$ & $30.99 \pm 0.23 a$ \\
\hline & 2 & $31.07 \pm 0.82 a$ & $31.32 \pm 0.29 a b$ & $31.30 \pm 1.31 \mathrm{a}$ & $30.88 \pm 0.34 a b$ \\
\hline & 4 & $30.57 \pm 0.67 a$ & $31.18 \pm 1.40 b$ & $31.03 \pm 0.42 a$ & $30.13 \pm 0.32 \mathrm{ac}$ \\
\hline & 6 & $30.46 \pm 0.60 \mathrm{a}$ & $30.24 \pm 0.75 a$ & $30.30 \pm 0.82 a$ & $30.56 \pm 0.27 \mathrm{ac}$ \\
\hline & 8 & $29.90 \pm 1.05 a$ & $31.03 \pm 1.12 a b$ & $30.60 \pm 1.77 a$ & $30.29 \pm 0.16 \mathrm{ac}$ \\
\hline & 10 & $30.10 \pm 1.29 a$ & $29.37 \pm 0.71 a b$ & $29.63 \pm 0.45 \mathrm{ac}$ & $31.05 \pm 0.21 \mathrm{ab}$ \\
\hline & 12 & $30.80 \pm 0.78 a$ & $30.57 \pm 0.97 a b$ & $30.22 \pm 0.47 a$ & $30.64 \pm 0.41 \mathrm{ac}$ \\
\hline & 14 & $30.70 \pm 0.36 a$ & $30.67 \pm 0.65 \mathrm{ac}$ & $30.53 \pm 0.60 \mathrm{a}$ & $30.25 \pm 0.23 \mathrm{ac}$ \\
\hline \multirow[t]{8}{*}{ Gluten index (\%) } & 0 & $48.09 \pm 0.84 a$ & $48.09 \pm 0.84 a$ & $48.09 \pm 0.84 a$ & $48.09 \pm 0.84 a$ \\
\hline & 2 & $47.47 \pm 1.09 \mathrm{~b}$ & $47.71 \pm 2.55 b$ & $49.61 \pm 1.51 a b$ & $50.20 \pm 1.01 b$ \\
\hline & 4 & $48.82 \pm 1.75 \mathrm{e}$ & $50.06 \pm 1.06 \mathrm{bc}$ & $51.26 \pm 0.41 \mathrm{ab}$ & $53.97 \pm 0.58 c$ \\
\hline & 6 & $49.41 \pm 1.19 c$ & $51.40 \pm 1.78 \mathrm{~cd}$ & $53.30 \pm 1.05 b$ & $63.89 \pm 0.21 \mathrm{bd}$ \\
\hline & 8 & $50.32 \pm 0.92 e$ & $53.35 \pm 1.43 d$ & $63.66 \pm 1.53 c$ & 63. $14 \pm 0.48 \mathrm{bc}$ \\
\hline & 10 & $51.77 \pm 2.64 d$ & $54.75 \pm 2.01 \mathrm{~cd}$ & $62.21 \pm 0.68 b c$ & $62.73 \pm 0.51 \mathrm{bd}$ \\
\hline & 12 & $55.06 \pm 1.95 \mathrm{e}$ & $56.88 \pm 0.87 c d$ & $63.38 \pm 0.59 b c$ & $63.62 \pm 0.27 d$ \\
\hline & 14 & $57.30 \pm 1.48 \mathrm{e}$ & $58.90 \pm 2.55 \mathrm{e}$ & $63.40 \pm 0.60 \mathrm{~cd}$ & $63.06 \pm 0.48 \mathrm{bd}$ \\
\hline \multirow{8}{*}{$\begin{array}{l}\text { Sodium dodecyl sulphate } \\
\text { sedimentation value (\%) }\end{array}$} & 0 & $29.17 \pm 1.04 \mathrm{~h}$ & $29.17 \pm 1.04 \mathrm{~h}$ & $29.17 \pm 1.04 \mathrm{~h}$ & $29.17 \pm 1.04 \mathrm{~g}$ \\
\hline & 2 & $29.43 \pm 0.60 \mathrm{gh}$ & $30.33 \pm 1.15 f g h$ & $30.83 \pm 0.76 f g h$ & $31.17 \pm 0.29 f g$ \\
\hline & 4 & $30.33 \pm 0.58 \mathrm{fg}$ & $31.33 \pm 0.58 \mathrm{efg}$ & $31.67 \pm 1.15 \mathrm{efg}$ & $32.67 \pm 2.00 \mathrm{ef}$ \\
\hline & 6 & $31.50 \pm 0.87 \mathrm{de}$ & $32.0 \pm 0.00 \mathrm{ef}$ & $32.33 \pm 0.58 \mathrm{ef}$ & $34.00 \pm 1.00 \mathrm{de}$ \\
\hline & 8 & $32.10 \pm 0.36 \mathrm{de}$ & $32.93 \pm 1.01 \mathrm{~cd}$ & $34.33 \pm 2.08 \mathrm{~cd}$ & $37.17 \pm 0.29 b c$ \\
\hline & 10 & $33.27 \pm 0.46 \mathrm{bc}$ & $33.83 \pm 0.76 a b c$ & $35.67 \pm 0.58 \mathrm{abc}$ & $38.67 \pm 0.58 a b$ \\
\hline & 12 & $34.17 \pm 0.29 a b$ & $35.00 \pm 0.00 \mathrm{ab}$ & $36.33 \pm 0.76 \mathrm{ab}$ & $39.50 \pm 0.50 a b$ \\
\hline & 14 & $34.60 \pm 0.53 a$ & $36.00 \pm 0.50 \mathrm{a}$ & $37.27 \pm 0.46 a$ & $40.67 \pm 1.15 a$ \\
\hline \multirow[t]{8}{*}{ Swelling index of glutenin } & 0 & $2.91 \pm 0.12 b$ & $2.91 \pm 0.12 b$ & $2.91 \pm 0.12 b$ & $2.91 \pm 0.12 f$ \\
\hline & 2 & $2.91 \pm 0.10 \mathrm{~b}$ & $2.98 \pm 0.11 b c$ & $3.05 \pm 0.11 \mathrm{be}$ & $3.21 \pm 0.13 \mathrm{cf}$ \\
\hline & 4 & $2.98 \pm 0.12 b$ & $3.05 \pm 0.13 c$ & $3.27 \pm 0.12 e$ & $3.4 \pm 0.11 b c$ \\
\hline & 6 & $3.12 \pm 0.11 b c$ & $3.24 \pm 0.12 \mathrm{~cd}$ & $3.29 \pm 0.13 \mathrm{ef}$ & $3.84 \pm 0.14 \mathrm{de}$ \\
\hline & 8 & $3.27 \pm 0.10 \mathrm{~cd}$ & $3.29 \pm 0.11 b c$ & $3.50 \pm 0.11 b c$ & $3.86 \pm 0.12 d$ \\
\hline & 10 & $3.32 \pm 0.12 b c$ & $3.34 \pm 0.15 a$ & $3.52 \pm 0.14 b c$ & $3.85 \pm 0.11 \mathrm{def}$ \\
\hline & 12 & $3.35 \pm 0.10 \mathrm{ac}$ & $3.37 \pm 0.10 \mathrm{ac}$ & $3.52 \pm 0.12 \mathrm{~cd}$ & $3.86 \pm 0.13 \mathrm{~cd}$ \\
\hline & 14 & $3.36 \pm 0.11 b c$ & $3.37 \pm 0.11 \mathrm{~cd}$ & $3.61 \pm 0.10 b c$ & $3.89 \pm 0.15 b c$ \\
\hline
\end{tabular}

$\mathrm{RH}$, contents of wet gluten decreased slightly with storage time. As shown Table 1, the change pattern of GI values in different storage environments is different. GI gradually increased for WT1 and WT2 samples in the whole storage stage. During the initial storage phage for WT3 and WT4 samples, GI increased significantly $(P<0.05)$. The GI reached to the highest values (63.66\% and 63.89\%) in WT3 and WT4 samples stored for 8 weeks and 6 weeks, respectively. WT4 sample reached the highest GI in the shortest time. GI is a measurement of wheat protein that provides a simultaneous determination of gluten quality and quantity (AACCI,
2010). The GI value expresses the weight percentage of the wet gluten remaining on a sieve after automatic washing with salt solution and centrifugation. The initial increase in gluten index indicated the improvement in gluten quality during postharvest wheat maturation (Elizabet et al., 2014). In this period, polymerisation and macromolecular redistribution of gluten proteins occurred and then progressively increases and as a consequence increase the proportion of gluten retained on the sieve (Aja et al., 2004; Elizabet et al., 2014). 


\section{Swelling index of glutenin in stored wheat}

Table 1 presents the changes in swelling index of glutenin (SIG) of wheat flour for the four samples in postharvest maturation. SIG for all wheat samples rose with storage time. Significant increase in SIG for WT4 was found during maturation compared with the other three samples. At 12 weeks of storage, SIG was 3.86, while SIGs of WT1, WT2 and WT3 were 3.35, 3.37 and 3.52, respectively. SIG for WT4 nearly reached the highest value at 6 weeks of storage, and then slowly rose with storage time. However, time of SIGs reaching the highest value for other three samples was late than WT4. The SIG can predict of wheat quality, the dough characteristics and the food quality, quickly and simply. SIG was generally used to assess the suitability as a screening procedure for wheat gluten strength. The insoluble glutenin was the protein fraction most responsible for the SIG value and gluten strength (Wang et al., 2007).

\section{SDS sedimentation value of stored wheat}

Sedimentation tests were generally used to characterise wheat flours and aimed to predict wheat processing, gluten quality and end-product qualities (Oelofse et al., 2010). It measures the sedimentation volume of an acidified suspension of wheat flour. It is a relatively low-cost, less time-consuming test that requires low manpower, is inexpensive and requires no elaborate laboratory equipment compared with other quality tests. It has proved to be a reliable, highly reproducible quality test that generally gives a good indication of the end-use quality of wheat (Carter et al., 1999) especially in cases where the wheat has a low to medium protein content. Change in the SDS-SV of wheat under four different storage conditions was shown in Table 1. According to table1, at $12^{\text {th }}$ week of storage, the SDS-SV for WT1, WT2, WT3 and WT4 increased by $5.43,6.83,8.1$ and $11.5 \mathrm{ml}$, respectively. Besides, SDS-SV for WT4 reached $37.17 \mathrm{ml}$ at $8^{\text {th }}$ week of storage. It meant that SDS-SV reached a maximum value for wheat stored in condition of higher temperature and higher moisture in short time compared to wheat stored under lower temperature and lower moisture. It is reported that, as a function of heating time when dry gluten was heated at $80^{\circ} \mathrm{C}$, the SDS-SV initially increased until it reached the maximum value, and further heat treatment resulted in decreased SDS-SV (Veraverbeke et al., 1997). The SDSSV was positively related to the baking quality of wheat flour (Carter et al., 1999). The baking quality and gluten quality are mainly governed by storage protein content and composition (Taenzler et al., 2002). SDS-SV reflected not only differences in protein content, but also differences in protein quality (Carter et al., 1999).
A

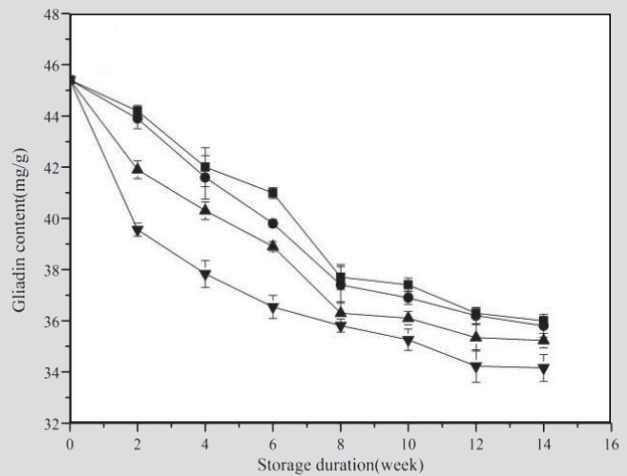

C

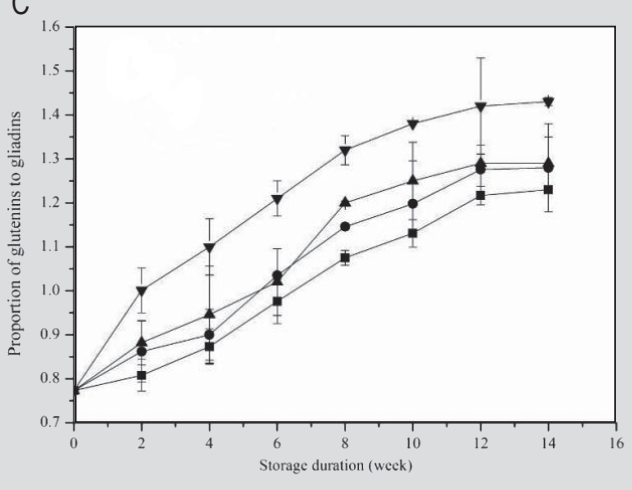

B

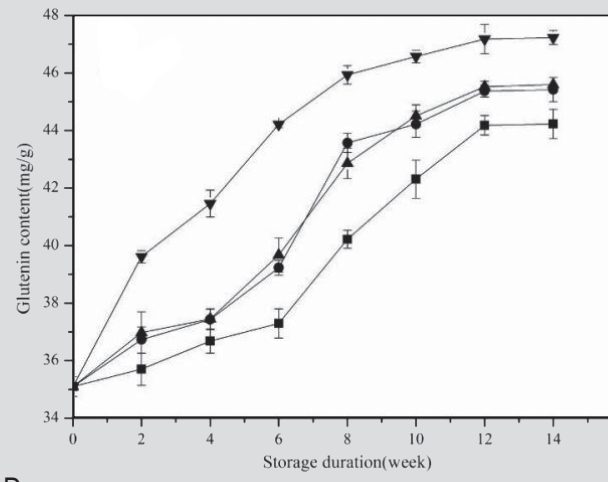

D

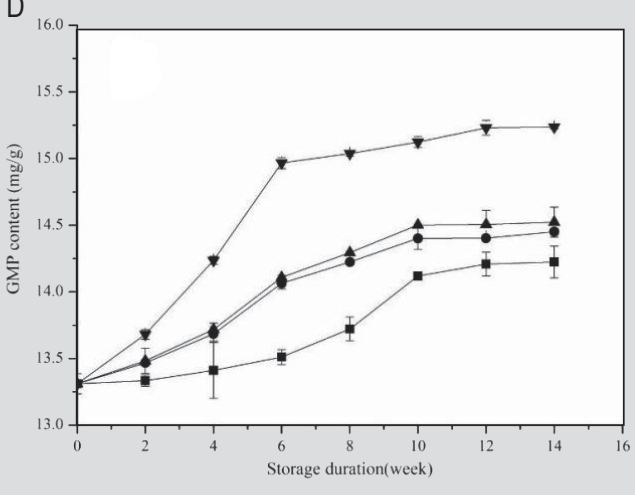

WT1

- WT2

$\Delta$ WT3

$\nabla$ WT4

Figure 1. Changes in content of different protein fractions during postharvest wheat maturation. (A) gliadin; (B) glutenin; (C) ratio of glutenin and gliadin; (D) glutenin macropolymer (GMP). The values in this figure are means of triplicates. 


\section{Change in content of gluten protein fractions}

During wheat postharvest maturation, the obvious changes in content of gliadin, glutenin and SDS-insoluble glutenin (GMP) were found (Figure 1). The content of gliadins for the four wheat samples decreased with storage time (Figure 1A). After storage for 12 weeks, gliadin content began to keep in relative constant level. The content of glutenin and GMP, proportion of glutenins to gliadins increased during storage (Figure 1B-D). It is shown that during postharvest maturation, the components of gluten protein changed continuously. Content of proteins in wheat flour does not play the key determinant role in flour performance; rather, flour quality is determined by certain protein sub-fractions deduced from gluten (Anjum et al., 2007). These wheat gluten proteins can be classified into two main sub-groups: gliadins and glutenins (Osborne, 1907). Gliadins confer viscosity and extensibility properties to the dough, whereas glutenins is the major components that impart strength and elasticity to the dough (Wieser, 2007). The variation of size and composition of GMP was correlation with a key technological quality parameter of wheat (Don, 2005). It is very interesting to study the change of polymer content, polymer size, polymer including subunit composition in postharvest maturation. Significant increase $(P<0.01)$ in GMP content for WT4 was found in initial 6 weeks of storage compared with the other three wheat samples. And then there were no obvious alteration in GMP content with long time of storage. It was in consonance with change in SIG and SDS-SV mentioned above. The temperature and drought had an important effect on the aggregation of gluten proteins in the developing wheat grain. Particularly, drought caused the early onset of the rapid polymerisation of gluten proteins (Carceller and Aussenac, 2001). A significant change in protein solubility of wheat kernel samples kept at higher temperature was observed when stored 4 and $30{ }^{\circ} \mathrm{C}$ for 270 days (Wilkes and Copeland, 2008). The profiling and identification of gluten proteins revealed that the formation of GMP was an increase in the content of high molecular weight glutenin subunits or conversion of gliadin fractions during postharvest wheat maturation.

\section{The content of free sulfhydryl groups of glutenin macropolymer during the wheat postharvest maturation}

About the structure of the GMP, a number of models have been proposed for the polymeric structure of glutenin. Most of structural models proposed the backbone of GMP was composed of HMW-GS only or HMW-GS and LMW-GS, and in which, the GMP contained both inter- and intrachain disulphide bonds, as well as non-covalent interactions (Lindsay et al., 1999). Differences in the bonding properties of glutenin subunits were thought to account for differences in the physiochemical properties of polymeric glutenin, which, in turn, accounted for variation in the functional properties of dough. Effect of storage duration, temperature, and relative humidity on the contents of $\mathrm{SH}$ groups and disulphide bonds of GMP was shown in Figure 2. The content of SH groups in GMP for the four wheat samples decreased during postharvest maturation (Figure 2A). Significant reduction $(P<0.05)$ in the content of free $\mathrm{SH}$ was found for WT4 during the initial 6 weeks of storage. The contents of free $\mathrm{SH}$ for the other three samples slowly reduced during the whole maturation. Contrary to the content of free $\mathrm{SH}$, the contents of disulphide bonds (S-S) of GMP rose from 0.142 to $0.173 \mathrm{mmol} / \mathrm{g}$ (WT1), 0.185 $\mathrm{mmol} / \mathrm{g}$ (WT2), $0.194 \mathrm{mmol} / \mathrm{g}$ (WT3) and $0.251 \mathrm{mmol} / \mathrm{g}$ (WT4) during the total period of storage. A significant increase $(P<0.05)$ in the content of $S-S$ bond was noticed for WT4 during the initial 6 weeks of storage. The prolongation of storage time resulted in slow increase in the content of
A

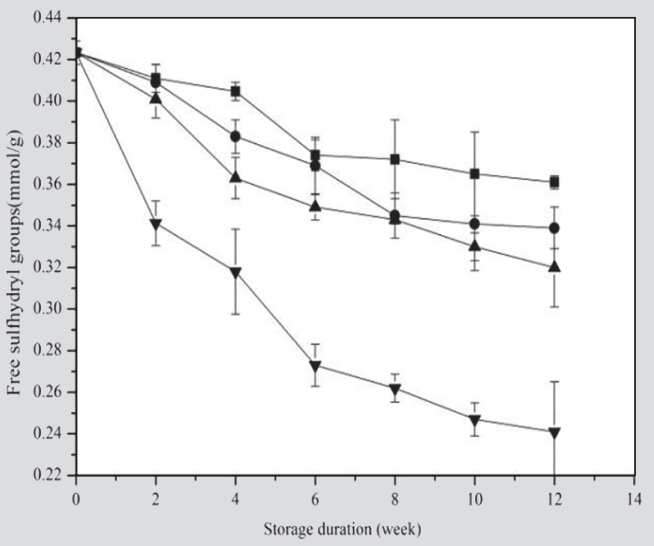

B

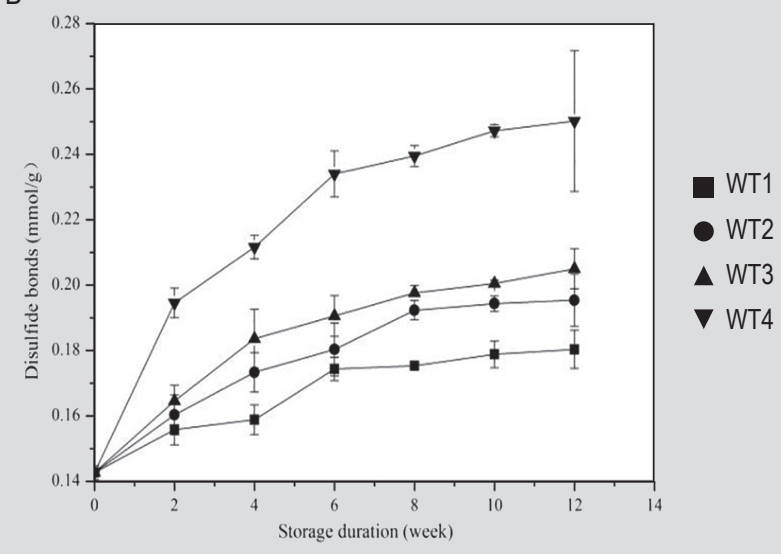

Figure 2. Changes in free sulfhydryl groups and disulphide bonds of glutenin macropolymer (GMP) during wheat postharvest maturation (mmol/g GMP). (A) is free sulfhydryl groups, and (B) is disulphide bonds. 
S-S bond. It was in agreement with the GMP contents. It was suggested that the oxidisation of free $\mathrm{SH}$ into SS bond in GMP during the wheat maturation. In addition, some of HMW-GS and LMW-GS in glutenins may incorporate into the previous GMP through the SH-SS exchange during the postharvest wheat maturation. Therefore, larger particle of GMP formed. The rearrangement of GMP during wheat maturation in the field occurred to some extent, which resulted from $\mathrm{SH} / \mathrm{SS}$ exchange and resulted in the increased number of SS bonds (Johansson et al., 2013). According to our results, these mechanisms probably continued during the wheat postharvest maturation process as reported by Tomić et al. (2013). Moreover, the increase in SIG, SDS sedimentation value and GMP content could be explained as a result of strengthen in structural linkage within GMP.

\section{Subunits composition of glutenin macropolymer}

To understand the effect of postharvest maturation on composition and structure of GMP, SDS-PAGE was carried out to analyse the change in subunits of GMP. The SDSPAGE profile of GMP under reducing conditions was shown in Figure 3. The GMP showed the presence of both HMW-GS (between 85 and $120 \mathrm{KDa}$ ) and LMWGS. A typical difference among these four wheat samples was the presence of a new high molecular weight band at approximately $145 \mathrm{KDa}$ in the upper region for WT4 after 4 weeks of postharvest maturation. Corresponding to this trend, some of molecular weight bands below $20 \mathrm{KDa}$ lost in this period (Figure 3D). At the same time, colour of some molecular weight bands between 85 and $120 \mathrm{KDa}$ turned darker (Figure 3D). Although no significant change in number of molecular weight bands was observed for WT1, WT2 and WT3, some bands in the LMW region were lost while some new bands appeared in the HMW region (Figure 3A-C). Moreover, some bands in the HMW region gradually turned darker in colour with storage time. It was suggested that the change of GMP in wheat grains was obvious under the high temperature and humidity storage condition. The reason may be that some of LMWGS were incorporated into the aggregate, or that different HMW-GS and LMW-GS form more complex polymeric structures by S-S linkage that were assembled into GMP. In conclusion, and the assemble process of GMP depended on storage temperature, storage time and moisture content.

\section{Gluten protein distribution patterns by size-exclusion high performance liquid chromatography analysis}

Size-exclusion high performance liquid chromatography (SE-HPLC) can be used to analyse the size or molecular weight distribution of gluten proteins. Samples with smaller particle size are eluted out earlier than larger ones in SEHPLC (Cornec et al., 1994). The extractability of glutenin in SDS solutions presents a good indication of the crosslinkage degree (Hayta and Schofield, 2004). According to Figure 4, the SE-HPLC profiles of gluten proteins followed the same chromatogram pattern from the four samples. The peaks mainly included four fractions at a particular interval of elution time, the peaks F1 and F2 corresponded with HMW glutenin polymers and LMW glutenin polymers. It was well known that the polymeric and oligomeric glutenin fractions (F1 and F2) mainly contributed to GMP formation (Van Herpen et al., 2008). The third peak (F3 fraction)
A

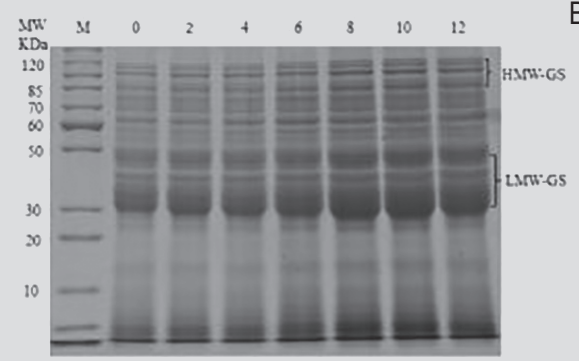

C

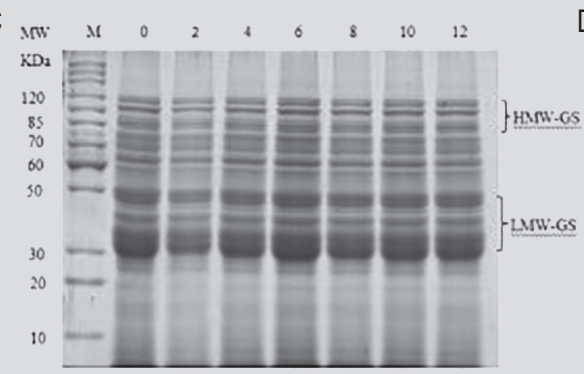

D
B $\mathrm{MW} \times \mathrm{M} \quad \mathrm{O} \quad 2 \quad 4 \quad 0 \quad 8 \quad 10 \quad 12$
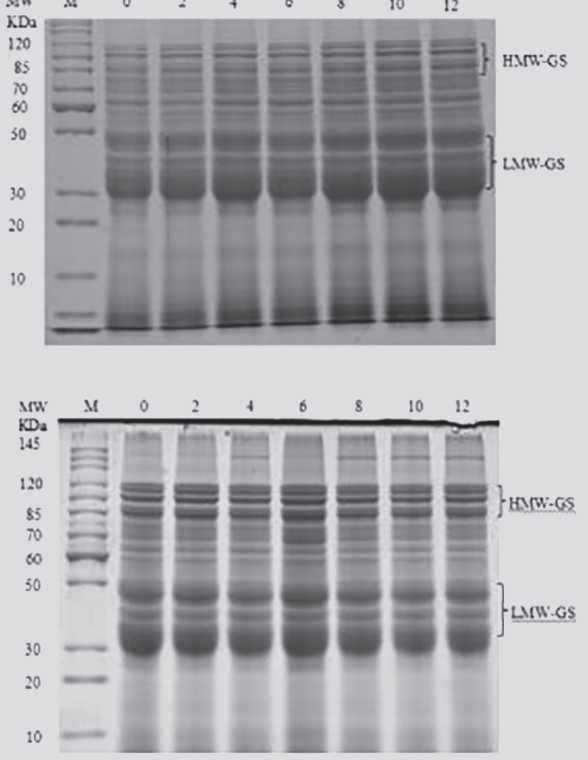

Figure 3. SDS-PAGE pattern of glutenin macropolymer of wheat during postharvest maturation. A, B, C and D represent WT1, WT2, WT3 and WT4, respectively. 
A

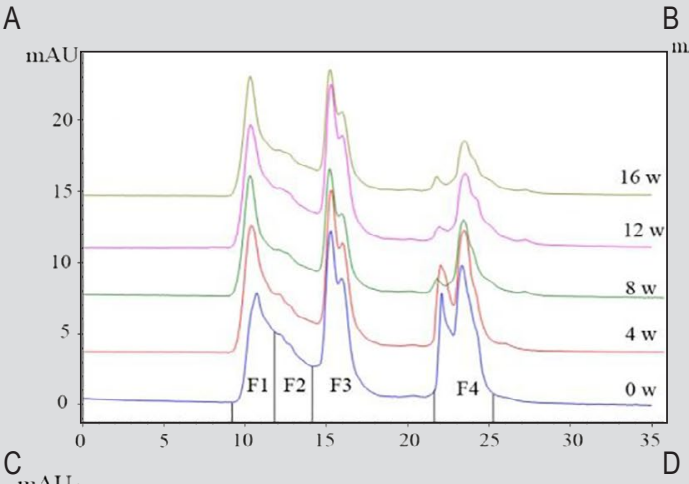

B
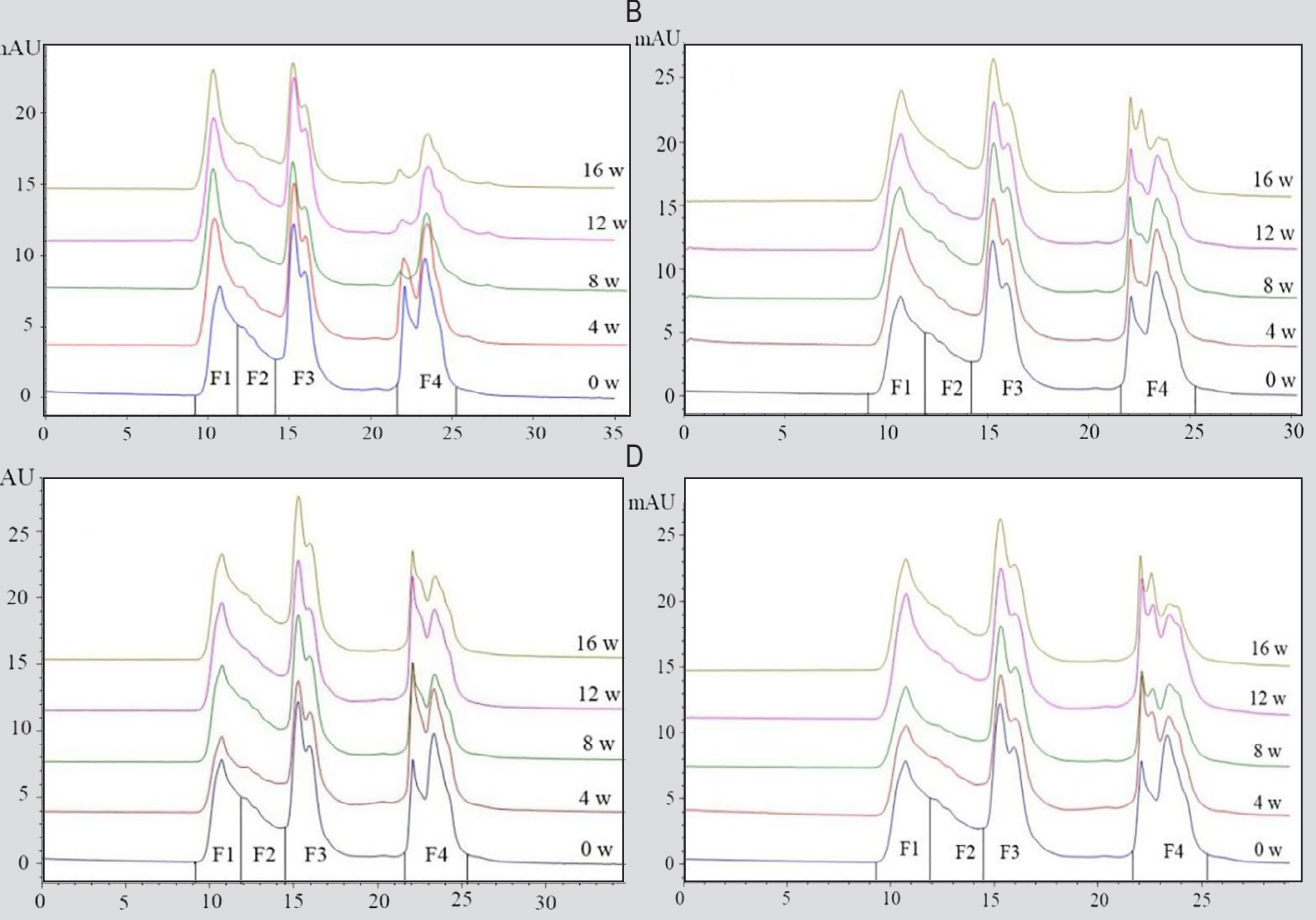

Figure 4. Molecular weight distribution of protein during postharvest maturation by size-exclusion high performance liquid chromatography. A, B, C and D represent WT1, WT2, WT3 and WT4, respectively.

was gliadin, while other peak (F4) represented albumin and globulin fractions. The shape and area of F4 had no obvious change in storage for the four samples. Decrease in area of F4 for the samples was noticed during storage. In contrast, the areas of F1 and F2 increased during the wheat postharvest maturation. At 16 weeks of wheat storage, the relative proportion of $\mathrm{F} 3$ was quiet low in comparison to F1 and F2. The relative proportion of SE-HPLC peaks' area $\%$ eluted fractions is summed up in Figure 5. The change of F1, F2 and F3 was observed at 4 weeks, 8 weeks and 12 weeks of storage. The percentage yield of large polymeric protein significantly increased at 4 weeks $(30.74,35.35$, 34.99 and 39.35, respectively). Afterward, it continued to increase slowly until 16 weeks of storage. The F3 decreased significantly at 4 weeks of storage, and then slowly declined. The increase in small polymeric protein was observed with storing time. All samples reached their maximum at 16 weeks of storage in $\mathrm{F} 1$ and descend to minimum in F3. Moreover, significant difference among these four fractions was also observed for the four samples at the same time of storage. At 16 weeks of storage, F1 exhibited the lowest area (33.793) in WT1, while the highest area of F3 (19.544). Nevertheless, F1 of WT4 sample exhibited an increment from 27.85 to $45.54, \mathrm{~F} 3$ showed a decrement from 26.05 to 12.98 . These revealed that the presence of higher proportion of polymeric glutenins and lower proportion of monomeric gliadins. It is indicated that the content of large polymeric protein and small polymer protein increased, and content of monomeric gliadins decreased during the wheat postharvest maturation.

\section{Conclusion}

The physicochemical properties of freshly-harvested wheat were greatly modified during the postharvest maturation at four different conditions of storage (WT1, WT2, WT3 and WT4). During wheat postharvest maturation (in initial storage period), rearrangement or polymerisation of GMP was observed resulted from interaction of free $\mathrm{SH}$ and S-S bond. This led to the great increase of GI, SIG and SDS-SV, indicating that the quality of freshly-harvested wheat improved significantly during maturation. The rearrangement or polymerisation of GMP was also found in the increase in the contents of glutenin, ratio of glutenin and gliadin, and GMP, and the decline of gliadin content of wheat during storage. Moreover, polymerisation of GMP was indicated in SDS-PAGE profiles and SE-HPLC patterns, especially for WT3 and WT4 samples. The results indicated that some HMW-GS only or HMW-GS and LMW-GS of glutenins were assembled into larger GMP by S-S linage. The change in structure and subunit composition of glutenin maybe associated with the quality improvement of wheat during the postharvest maturation. The present study provided useful information about the modification of the structure and composition of GMP of the postharvest wheat maturation under the selected storage conditions. 


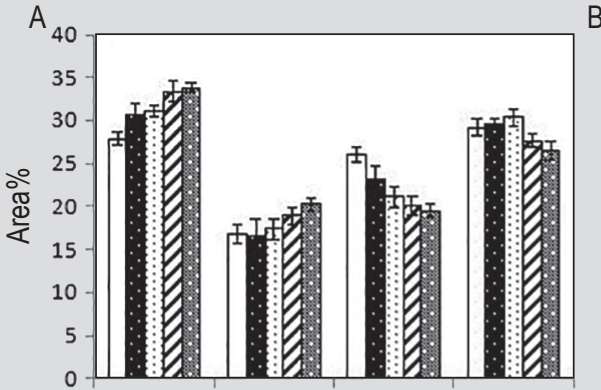

F1

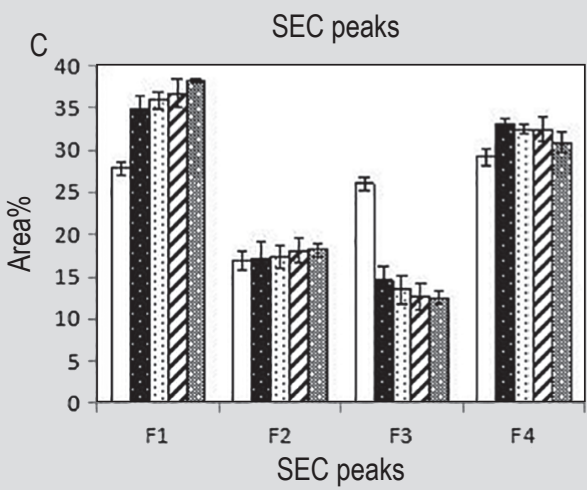

B

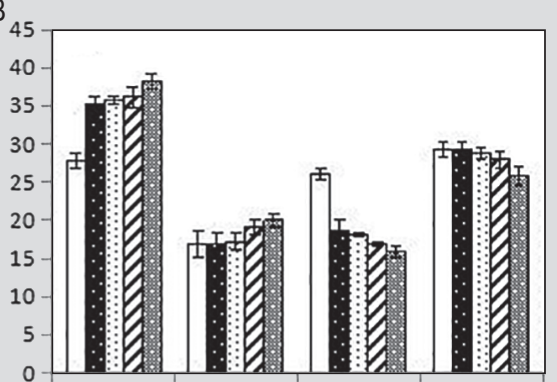

F1

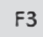

F4

$D_{50}$

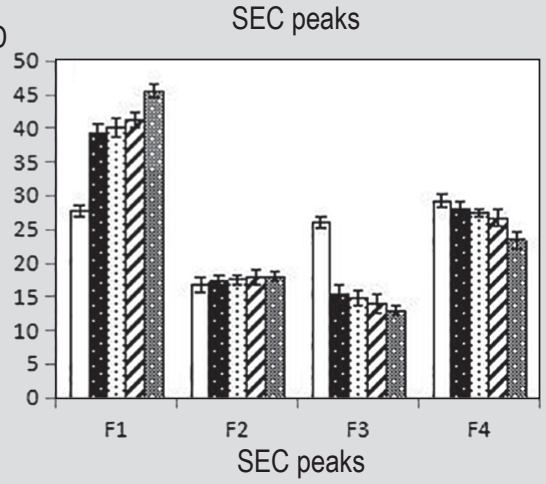

$\square 0 w$

a. $4 w$

D $8 w$

प12w

16 w

Figure 5. Relative area \% of peaks obtained using size-exclusion high performance liquid chromatography. A, B, C and D represent four storage conditions of WT1, WT2, WT3 and WT4, respectively.

The present study confirmed the necessity of postharvest wheat maturation in order to make the technological quality improvement. In order to draw more reliable conclusions, further investigations should be made covering a wider range of wheat varieties from different gluten strength and different production years.

\section{Acknowledgements}

The authors thank the financial support of National Natural Science Foundation of China (No. 31771897), the Key Scientific Research Project of Universities in Henan Province (16A210018), and the Focus on Fostering Basic Research Fund of the Henan University of Technology (2013JCYJ05).

\section{References}

Aghababaei, A., Maftoonazad, N., Elhamirad, A. and Badii, F., 2017. Accelerated ageing of wheat grains: part I - influence on rheological properties of wheat flour. Journal of Cereal Science 77: 147-156.

Aja, S., Pérez, G. and Rosell, C.M., 2004. Wheat damage by Aelia spp. and Erygaster spp.: effects on gluten and water-soluble compounds released by gluten hydrolysis. Journal of Cereal Science 39: 187-193. American Association of Cereal Chemists International (AACCI), 2010. AACC approved method 38.12-02. AACCI, St. Paul, MN, USA.
Anderson, A.K. and Ng, P.K.W., 2007. Changes in disulfide and sulfhydryl contents and electrophoretic patterns of extruded wheat flour proteins. Cereal Chemistry 77: 354-359.

Anjum, F.M., Rafiq Khan, M., Din, A., Saeed, M., Pasha, I. and Umair Arshad, M., 2007. Wheat gluten: high molecular weight glutenin subunits-structure, genetics and relation to dough elasticity. Journal of Food Science 72: 56-63.

Bonfil, D.J. and Posner, E.S., 2012. Can bread wheat quality be determined by gluten index? Journal of Cereal Science 56: 115-118.

Carceller, J.L. and Aussenac, T., 2001. SDS-insoluble glutenin polymer formation in developing grains of hexaploid wheat: the role of the ratio of high to low molecular weight glutenin subunits and drying rate during ripening. Australian Journal of Plant Physiology 28: 193-201.

Carter, B.P., Morris, C.F. and Anderson, J.A., 1999. Optimizing the SDS sedimentation test for end-use quality selection in a soft white and club wheat-breeding program. Cereal Chemistry 76: 907-911.

Chaudhary, N., Dangi, P. and Khatkar, B.S., 2016. Assessment of molecular weight distribution of wheat gluten proteins for chapatti quality. Food Chemistry 199: 28-35.

Cornec, M., Popineau, Y. and Lefebvre, J., 1994. Characterisation of gluten subfractions by SE-HPLC and dynamic rheological analysis in shear. Journal of Cereal Science 19: 131-139.

Dachkevitch, T. and Autran, J.C., 1998. Prediction of baking quality of bread wheats in breeding programs by size-exclusion highperformance liquid chromatography. Cereal Chemistry 66: 448-456. 
Don, C., 2005. General discussion. In: Don, C. (ed.) Factors affecting the hyperaggregation of glutenin particles. $\mathrm{PhD}$-thesis, Wageningen University, Wageningen, the Netherlands, pp. 183-204.

Don, C., Lichtendonk, W.J., Plijter, J.J. and Hamer, R.J., 2003a. Glutenin macropolymer: a gel formed by particles. Journal of Cereal Science 37: 1-7.

Don, C., Lichtendonk, W.J., Plijter, J.J. and Hamer, R.J., 2003b. Understanding the link between GMP and dough: from glutenin particles in flour towards developed dough. Journal of Cereal Science 38: 157-165.

Dowell, F.E., Maghirang, E.B., Pierce, R.O., Lookhart, G.L., Bean, S.R., Xie, F., Caley, M.S., Wilson, J.D., Seabourn, B.W., Ram, M.S., Park, S.H. and Chung, O.K., 2008. Relationship of bread quality to kernel, flour, and dough properties. Cereal Chemistry 85: 82-91.

Elizabet, J.H., Jelena, T., Aleksandra, T., Sladana, R., Milica P., Dragan, Z., Miroslav, H. and Tamara, D.H., 2014. Content of free amino groups during postharvest wheat and flour maturation in relation to gluten quality. Food Chemistry 164: 158-165.

Graveland, A., Bosveld, P., Lichtendonk, W.J. and Moonen, J.H.E., 1982. Extraction and fractionation of wheat flour proteins. Journal of the Science of Food and Agriculture 33: 1117-1128.

Gupta, R.B., Khan, K. and MacRitchie, F., 1993. Biochemical basis of flour properties in bread wheat. I. Effects of variation in the quality and size distribution of polymeric protein. Journal of Cereal Science 18: 23-41.

Hall, G.M., 1996. Methods of testing protein functionality. M. Blackie Academic and Professional, London, UK, pp. 34-37.

Hayta, M. and Schofield, J.D., 2004. Heat and additive induced biochemical transitions in gluten from good and poor bread making quality wheats. Journal of Cereal Science 40: 245-256.

Janić, H.E., Tomić, J., Torbica, A., Rakita, S., Pojić, M., Zivančev, D., Hadnađev, M. and Dapčević, H.T., 2014. Content of free amino groups during postharvest wheat and flour maturation in relation to gluten quality. Food Chemistry 164: 158-165.

Johansson, E., Malik, A.H., Hussain, A., Rasheed, F., Newson, W.R., Plivelic, T., Hedenqvist, M.S., Gällstedt, M. and Kuktaite, R., 2013. Wheat gluten polymer structures: the impact of genotype, environment, and processing on their functionality in various applications. Cereal Chemistry 90: 367-376.

Koga, S., Böcker, U., Wieser, H., Koehler, P., Uhlen, A.K. and Moldestad, A., 2017. Polymerisation of gluten proteins in developing wheat grain as affected by desiccation. Journal of Cereal Science 73: 122-129.

Labuschagne, M.T., Meintjes, G. and Groenewald, F.P.C., 2006. The influence of different nitrogen treatments on the size distribution of protein fractions in hard and soft wheat. Journal of Cereal Science 43: $315-321$
Lindsay, M.P. and Skerritt, J.H., 1999. The glutenin macropolymer of wheat flour doughs: structure-function perspectives. Trends in Food Science and Technology 10: 247-253.

MacRitchie, F., 1980. Studies of gluten protein from wheat flours. Cereal Foods World 25: 382-385.

Oelofse, R.M., Labuschagne, M.T. and Van Deventer, C.S., 2010. Influencing factors of sodium dodecyl sulfate sedimentation in bread wheat. Journal of Cereal Science 52: 96-99.

Osborne, T.B., 1907. The protein of the wheat kernel. Publication 84. Carnegie institute of Washington, Washington, DC, USA.

Peterson, C.J., Johnson, V.A. and Mattern, P.J., 1986. Influence of cultivar and environment on mineral and protein concentration of wheat flour, bran and grain. Cereal Chemistry 63: 183-186.

Pomeranz, Y., 1988. Composition and functionality of wheat four components. In: Pomeranz, Y. (ed.) Wheat: chemistry and technology II, $3^{\text {rd }}$ edition. AACC, St. Paul, MN, USA, pp. 219-370.

Sapirstein, H.D. and Suchy, J., 1999. SDS protein gel test for prediction of bread loaf volume. Cereal Chemistry 76: 164-172.

Song, Y. and Zheng, Q., 2007. Dynamic rheological properties of wheat flour dough and proteins. Trends in Food Science and Technology 18: 132-138.

Taenzler, B., Esposti, R.F., Vaccino, P., Brandolini, A., Effgen, S., Heun, M., Schäfer Pregl, R., Borghi, B. and Salamini, F., 2002. A molecular linkage map of einkorn wheat: mapping of storage-protein and soft-glume genes and bread making QTLs. Genetical Research 80: 131-143.

Tomić, J., Pojić, M., Torbica, A., Rakita, S., Živančev, D. and Hajnal, E.J., 2013. Changes in the content of free sulphydryl groups during postharvest wheat and flour maturation and their influence on technological quality. Journal of Cereal Science 58: 495-501.

Van Herpen, T.W.J.M., Cordewener, J.H.G., Klok, H.J., Freeman, J., America, A.H.P., Boscha, D., Smulders, M.J.M., Gilissen, J.W.J., Shewry, P.R. and Hamer, R.J., 2008. The origin and early development of wheat glutenin particles. Journal of Cereal Science 48: 870-877.

Veraverbeke, W.S., Roels, S.P. and Delcour, J.A., 1997. Heat-induced changes in sodium dodecyl sulphate-sedimentation volume and functionality of vital wheat gluten. Journal of Cereal Science 26: 177-181.

Wang, J.S., Zhao, M.M. and Zhao, Q.Z., 2007. Correlation of glutenin macropolymer with viscoelastic properties during dough mixing. Journal of Cereal Science 45: 128-133.

Weegels, P.L., Hamer, R.J. and Schofield, J.D., 1996. Functional properties of wheat glutenin. Journal of Cereal Science 23: 1-17.

Wieser, H., 2007. Chemistry of gluten proteins. Food Microbiology 24: 115-119.

Wilkes, M. and Copeland, L., 2008. Storage of wheat grains at elevated temperatures increases solubilization of glutenin subunits. Cereal Chemistry 85: 335-338. 